\title{
Microstructural Evolution of Multi-Pass Caliber-Rolled Mg-Sn and Mg-Sn-Mn Alloys
}

\author{
Jinyeong Yu ${ }^{1,2}$, Hongxin Liao ${ }^{3}$, Jeong Hun Lee ${ }^{2}$, Young Hoon Moon ${ }^{1}{ }^{\mathbb{C}}$, Hyun Sik Yoon ${ }^{4}$, \\ Jonghyun Kim ${ }^{3, *}$ and Taekyung Lee ${ }^{1, * \mathbb{D}}$ \\ 1 School of Mechanical Engineering, Pusan National University, Busan 46241, Korea; \\ cosmicbird@pnu.ac.kr (J.Y.); yhmoon@pusan.ac.kr (Y.H.M.) \\ 2 Advanced Forming Process R\&D Group, Korea Institute of Industrial Technology, Ulsan 44413, Korea; \\ pocion@kitech.re.kr \\ 3 College of Materials Science and Engineering, Chongqing University, Chongqing 400044, China; \\ hongxinliao@foxmail.com \\ 4 Department of Naval Architecture and Ocean Engineering, Pusan National University, Busan 46241, Korea; \\ lesmodel@pusan.ac.kr \\ * Correspondence: joindoc@cqu.edu.cn (J.K.); taeklee@pnu.ac.kr (T.L.); \\ Tel.: +86-186-2334-1487 (J.K.); +82-51-510-2985 (T.L.)
}

Received: 6 August 2020; Accepted: 4 September 2020; Published: 8 September 2020

check for updates

\begin{abstract}
Multi-pass caliber rolling has proven its vast potential for ultrafine-scale grain refinement and mass production of various metals. Nevertheless, the studies related to Mg alloys have primarily focused only on a few commercial materials, such as AZ31 and ZK60 Mg alloys. This is the first study to investigate caliber-rolled Mg-1Sn (TM10) and Mg-1Sn-1Mn (TM11) alloys. Specifically, this work aims to elucidate the microstructural characteristics of these alloys, including grain refinement, recrystallization, and texture development. Such features were discussed from the viewpoints of alloying effects (i.e., Sn and $\mathrm{Mn}$ ) and mechanical effects (i.e., caliber-rolling strains). The combination of the addition of $\mathrm{Mn}$ and high-redundant strain results in effective grain refinement of the caliber-rolled TM11 Mg alloys. In addition, both TM10 and TM11 Mg alloys exhibit a unique split basal texture, wherein the basal poles are tilted in the plane normal to the rolling direction.
\end{abstract}

Keywords: magnesium; Mg-Sn-Mn; caliber rolling; grain refinement; texture

\section{Introduction}

Light-weight $\mathrm{Mg}$ alloys have attracted significant attention from the automotive industry, whose objectives are to enhance fuel efficiency and comply with environmental regulations [1]. To facilitate extensive applications of $\mathrm{Mg}$ alloys, researchers have endeavored to resolve various issues related to these alloys, such as low strength, poor formability, and low corrosion resistance. One approach is to develop a new alloying system that includes a variety of rare-earth elements (RE), including $\mathrm{Y}, \mathrm{Ce}, \mathrm{Nd}$, and $\mathrm{Gd}$. For example, Golrang et al. [2] confirmed that the strong grain-refining capability of RE enhanced the mechanical strength of $\mathrm{Mg}-\mathrm{Zn}-\mathrm{Ca}-\mathrm{RE}$ alloys; the ultimate tensile strength of an extruded $\mathrm{Mg}-4 \mathrm{Zn}-0.5 \mathrm{Ca}-0.5 \mathrm{RE}$ alloy was 3.11 times that of cast $\mathrm{Mg}$. $\mathrm{Mg}-\mathrm{Zn}-\mathrm{Y}-\mathrm{RE}$ alloys were proven to possess exceptional mechanical properties owing to the formation of a unique microstructure called "long-period stacking ordered phase" [3]. The beneficial effects of adding RE are also applicable for commercial Mg alloys, such as AZ31 and ZK60. The combined addition of Gd and Ca to AZ31 Mg alloy induced a simultaneous improvement in its strength and ductility owing to the suppressed activation of mechanical twinning [4]. An addition of $3 \%$ of Ce to a commercial ZK60 Mg alloy increased its yield and tensile strengths by $45 \%$ and $19 \%$, respectively [5]. These improvements 
were attributed to RE-induced grain refinement and increments in the volume fractions of $\mathrm{Mg}_{7} \mathrm{Zn}_{3}$ and $\mathrm{MgZn}_{2} \mathrm{Ce}$ precipitates. Nevertheless, the addition of RE would increase the material cost and hence, significantly limit the application of these alloys.

The other approach is to tailor the microstructure of commercial Mg alloys. Careful design of the thermomechanical processing route induces an optimized microstructural evolution and a resultant improvement in their mechanical properties [6-9]. A severe plastic deformation (SPD) process has been developed based on this approach. The SPD processes impose a considerable amount of plastic deformation on the metals and results in a grain refinement to the submicron scale [10]. Although the SPD processes successfully improve the mechanical properties, they are intrinsically unsuitable for continuous mass production. As an alternative, multi-pass caliber rolling (often called "groove rolling") has attracted attention because it is capable of not only significant grain refinement but also mass production [11]. Research on caliber-rolled Mg alloys has been limited compared to that on caliber-rolled ferrous alloys. Moreover, these studies have focused primarily on commercial AZ31 Mg alloys [12-16]. Only a few studies have recently investigated the effect of caliber rolling on other $\mathrm{Mg}$ alloys, such as ZK60 alloy [17,18], Mg-Mn alloy [19], and Mg-Al compound casting [20].

The Mg-Sn alloying system has a high potential for optimal degradation rate for biomedical applications [21]. Liao et al. [22] recently achieved an additional improvement in the mechanical properties by adding $1-2 \%$ of $\mathrm{Mn}$ to this alloying system (i.e., $\mathrm{Mg}-\mathrm{Sn}-\mathrm{Mn}$ alloys). The idea of using multi-pass caliber-rolled $\mathrm{Mg}-\mathrm{Sn}-\mathrm{Mn}$ as an alternative $\mathrm{Mg}$ alloy originated from their results. Hence, this study investigates the microstructural evolution of caliber-rolled $\mathrm{Mg}-\mathrm{Sn}$ and $\mathrm{Mg}-\mathrm{Sn}-\mathrm{Mn}$ alloys for the first time. This work aims to clarify the effect of each alloying element on grain refinement, recrystallization, and texture development. It also discusses the differences in the microstructures between the alloys subjected to caliber rolling and conventional extrusion.

\section{Materials and Methods}

$\mathrm{Mg}$ alloy ingots were fabricated using a semi-continuous casting machine (Chongqing Yuhua New Material Technology Co. Ltd., Chongqing, China) from high-purity $\mathrm{Mg}$, Sn, and Mg-3.25Mn (numbers indicate mass percentage) master alloy. Pure $\mathrm{Mg}$ was melted at $1013 \mathrm{~K}$ in Ar atmosphere using an electric furnace (Chongqing Yuhua New Material Technology Co. Ltd., Chongqing, China), followed by the melting of $\mathrm{Sn}$ and $\mathrm{Mg}-3.25 \mathrm{Mn}$ master alloy. The melt was then poured into a screw semi-continuous casting to produce cylindrical ingots with a diameter of $80 \mathrm{~mm}$. The chemical composition of the billets was measured using X-ray fluorescence spectrometry (Shimadzu, Kyoto, Japan) for two different alloys, Mg-1.01Sn (TM10) and Mg-1.02Sn-0.97Mn (TM11).

The ingots were machined into "stake" specimens for multi-pass caliber rolling. They consist of two sections with a length of $150 \mathrm{~mm}$ each, namely a conical head section with an inclination angle of $6^{\circ}$ and a cylindrical body section with a diameter of $26 \mathrm{~mm}$. These specimens were homogenized at $773 \mathrm{~K}$ for $24 \mathrm{~h}$, followed by water quenching. In a preliminary study, the samples heated at less than $673 \mathrm{~K}$ revealed the formation of internal cracks after a subsequent caliber rolling performed in an ambient atmosphere. Accordingly, the homogenized samples were soaked in a furnace at $673 \mathrm{~K}$ for $1 \mathrm{~h}$, and then directly inserted into the first caliber. Each stake was rotated counter-clockwise by $90^{\circ}$ around the rolling direction (RD) for each caliber-rolling pass. They were then reheated at $673 \mathrm{~K}$ for $5 \mathrm{~min}$ after the second and fourth passes of rolling. Henceforth, each caliber-rolled sample was denoted by the number of rolling passes applied to the sample; for example, "TM10-6P" represents the $\mathrm{Mg}-1.01 \mathrm{Sn}$ alloy specimen subjected to six passes of caliber rolling. An illustrative explanation for caliber rolling is presented with the dimensions of the caliber-rolled cross-sections (Figure 1). 


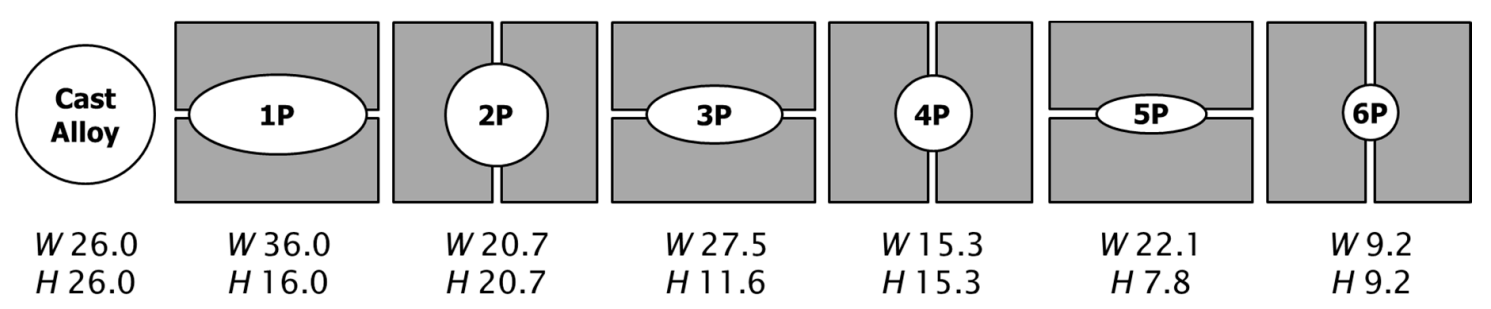

Figure 1. Changes in the cross-sectional area of the caliber-rolled $\mathrm{Mg}$ alloy specimens depending on the rolling pass. The gray area indicates a pair of rolls. $W$ and $H$ are the width and height of the cross-sectional area, respectively (unit: $\mathrm{mm}$ ).

Samples were obtained from the center of the cross-sectional area in the cylindrical body section for microstructural characterization. They were mechanically polished using emery paper from \#60 to \#4000 until no visible scratches remained on the surface. They were then subjected to electrolytic etching at $20 \mathrm{~V}$ for $60 \mathrm{~s}$ at $253 \mathrm{~K}$. The etchant consisted of $10 \mathrm{~g}$ of hydroxyquinoline (Chengdu Kelong Chemical Reagent Factory, Chengdu, China), $75 \mathrm{~g}$ of citric acid (Chengdu Kelong Chemical Reagent Factory, Chengdu, China), $41.5 \mathrm{~g}$ of sodium thiocyanate (Chongqing Chuandong Chemical Co. Ltd., Chongqing, China), $15 \mathrm{~mL}$ of perchloric acid (Chongqing Chuandong Chemical Co. Ltd., Chongqing, China), $18.5 \mathrm{~mL}$ of distilled water, $100 \mathrm{~mL}$ of propyl alcohol (Chongqing Chuandong Chemical Co. Ltd., Chongqing, China), and $800 \mathrm{~mL}$ of ethyl alcohol (Chongqing Chuandong Chemical Co. Ltd., Chongqing, China). The microstructures were investigated using a field-emission scanning electron microscope (Japan Electronics Co. Ltd., Tokyo, Japan), equipped with an energy dispersive spectroscope and electron backscatter diffraction (EBSD) system. The step size for the scanning was set to $0.5 \mu \mathrm{m}$.

\section{Results}

TM10 Mg alloys exhibited a clearly evident change in the microstructures depending on the strain applied during the caliber rolling (Figure 2). The TM10-1P sample showed coarse elongated grains with a size of $16.0 \mu \mathrm{m}$. The TM10-2P sample presented a significant grain refinement to a size of $5.5 \mu \mathrm{m}$, while maintaining the elongated grain morphology. This tendency was consistent with the average size of the transverse grains -7.79 and $4.74 \mu \mathrm{m}$ for TM10-1P and TM10-2P, respectively. The TM10-3P sample consisted of slightly larger grains with a size of $6.4 \mu \mathrm{m}$. It should also be noted that the grain morphology changed into equiaxed shapes in this sample. The TM10-4P, -5P, and -6P samples demonstrated similar microstructures (i.e., equiaxed grain structure) with decreasing grain sizes-3.9, 2.4, and $1.8 \mu \mathrm{m}$, respectively. No internal cracks were observed for the TM10 Mg alloys.

TM11 Mg alloys presented a similar evolution of microstructures; the grains were refined with an increasing number of caliber rolling passes (Figure 3). They also showed no visible cracks during the observation. The TM11-1P sample showed coarse elongated grains similar to the microstructure of TM10-1P. However, the alloy was distinguished by a heterogeneous distribution of grain sizes. Figure 3a shows a large elongated grain with a width of over $50 \mu \mathrm{m}$ as well as fine grains with a diameter of less than $10 \mu \mathrm{m}$. Despite the large grains, the average grain size of the TM11-1P sample ( $6.4 \mu \mathrm{m}$ for the EBSD measurement and $6.28 \mu \mathrm{m}$ for the transverse grain size) was lower than that of the TM10-1P sample $(16.0 \mu \mathrm{m}$ and $7.79 \mu \mathrm{m})$. TM11-3P and -5P demonstrated fine equiaxed grains with sizes of 2.6 and $1.5 \mu \mathrm{m}$, respectively. It should be noted that a few coarse and unrecrystallized grains remained in TM11 Mg alloys, even after five passes of deformation. 

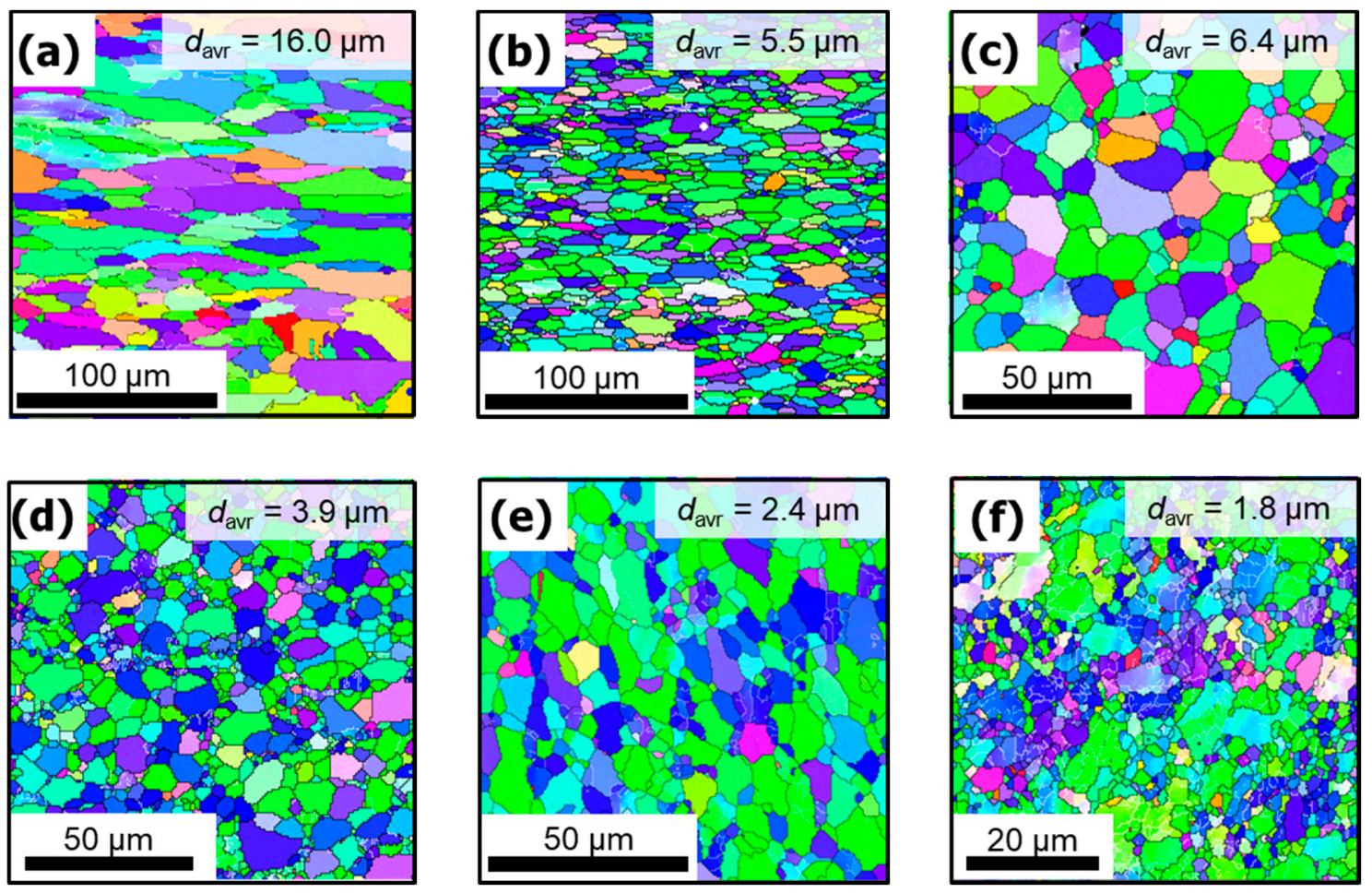

Figure 2. EBSD inverse pole figure maps of the investigated TM10 Mg alloys: (a) TM10-1P, (b) TM10-2P, (c) TM10-3P, (d) TM10-4P, (e) TM10-5P, and (f) TM10-6P. The images are normalized to the RD. " $d_{\mathrm{avr}}$ " indicates the average grain size, as determined by the EBSD analysis.
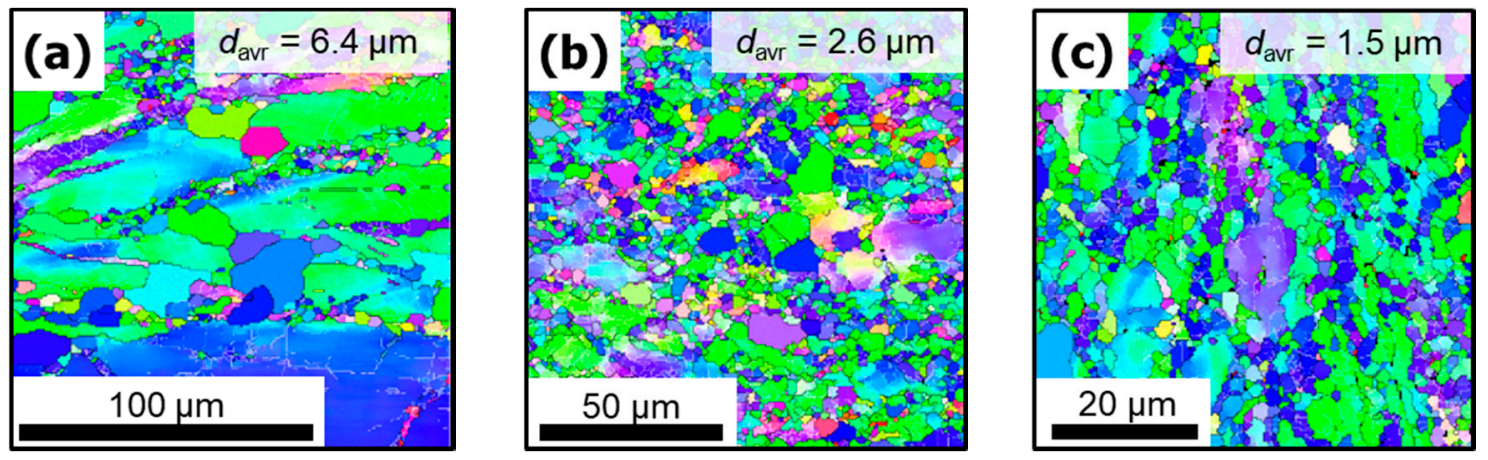

Figure 3. EBSD inverse pole figure maps of the investigated TM11 Mg alloys: (a) TM11-1P, (b) TM11-3P, and (c) TM11-5P. The images are normal to RD. " $d_{\mathrm{avr}}$ " indicates the average grain size, as determined by the EBSD analysis.

The average grain sizes of the investigated alloys are presented as a function of area reduction for quantitative comparison (Figure 4). The grain sizes of the TM11 Mg alloys were significantly lower than those of the TM10 Mg alloys. These results suggest a strong grain-refining capability of $1 \%-\mathrm{Mn}$ addition. It is of particular note that the caliber-rolled $\mathrm{Mg}$ alloys exhibited significantly smaller grains than those deformed by conventional extrusion. This was confirmed by comparing the present results with grain sizes of extruded TM10 and TM11 Mg alloys; they were homogenized under the same conditions used in this work, followed by extrusion at $573 \mathrm{~K}$ and a ram speed of $1 \mathrm{~m} \cdot \mathrm{min}^{-1}$ [22]. Area reduction of $96 \%$ caused by the extrusion resulted in a grain size of 13.1 and $2.7 \mu \mathrm{m}$ for TM10 and TM11, respectively. Both numbers were remarkably higher than those of the caliber-rolled $\mathrm{Mg}$ alloys subjected to an even lower area reduction and higher deformation temperature. The difference between these two processes is discussed further in Section 4 . 


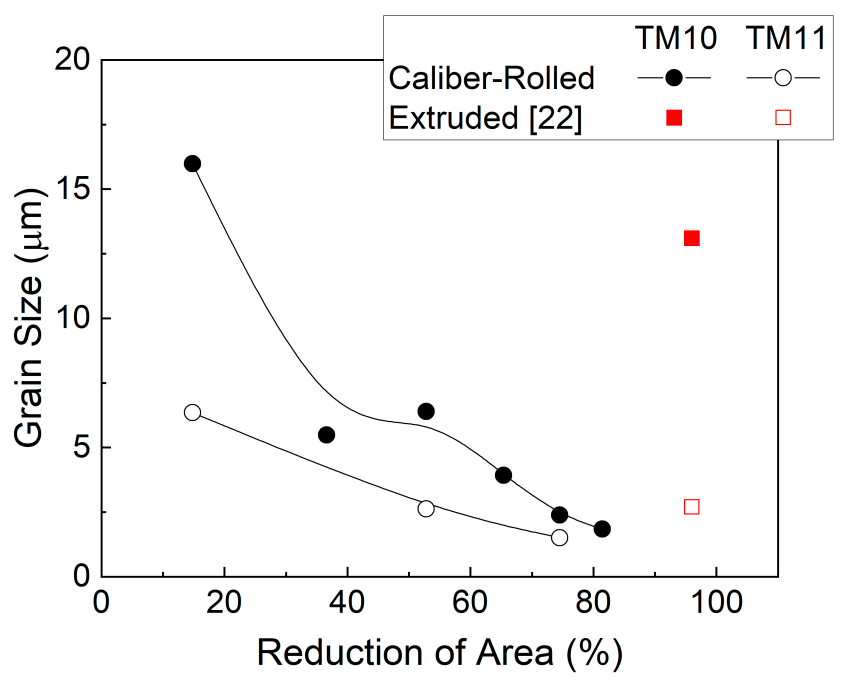

Figure 4. Grain sizes of the investigated TM10 and TM11 Mg alloys depending on the reduction in the area. Grain sizes of the extruded TM10 and TM11 Mg alloys [22] are also included for comparison.

The investigated TM10 Mg alloys demonstrated similar pole figures, suggestive of a comparable texture development (Figure 5). The basal poles were oriented perpendicular to the RD owing to the deformation imposed along the normal direction (ND) and transverse direction (TD). Only the TM10-1P sample showed incomplete perpendicularity between the basal poles and RD, as shown in Figure 5a. This could be attributed to the insufficient caliber-rolling strain, which also accompanied the imperfect grain refinement in this alloy, as mentioned above. Comparing the TM10-1P and -6P samples, the latter demonstrated a "split" texture. Texture intensity rarely presented a clearly evident trend depending on the number of caliber rolling passes.

(a)

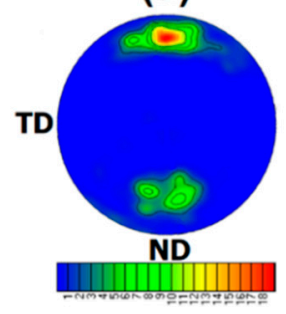

(b)

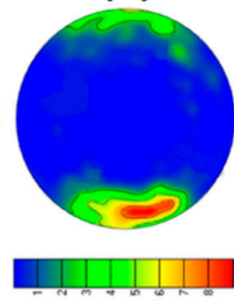

(c)

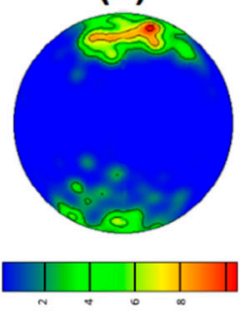

(d)

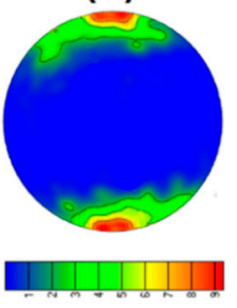

(e)

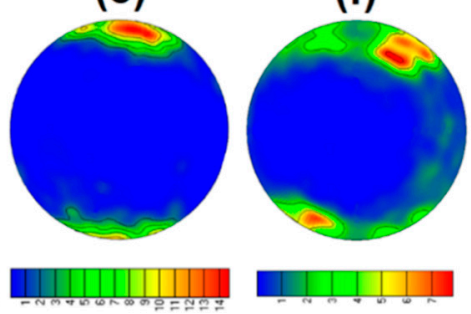

Figure 5. $\{0001\}$ pole figure maps of TM10 Mg alloys: (a) TM10-1P, (b) TM10-2P, (c) TM10-3P, (d) TM10-4P, (e) TM10-5P, and (f) TM10-6P. The images are taken normal to the RD.

The TM11 Mg alloys showed comparable trends in texture development in light of (i) the basal poles normal to the RD and (ii) split basal poles (Figure 6). It should be noted that the separated poles in the TM11-1P sample arose from the presence of large unrecrystallized grains in Figure 3a, rather than the split basal poles. TM11 Mg alloys also exhibited a weak relationship between the texture intensity and the number of caliber rolling passes. However, there was a clearly evident difference in the texture intensities between the TM10 and TM11 groups. The latter exhibited higher texture intensities (16.81-27.97) than those of the former (7.85-10.61), as seen in Figure 6d. This phenomenon was consistent with the results obtained from the extruded TM10 and TM11 Mg alloys [22]. 

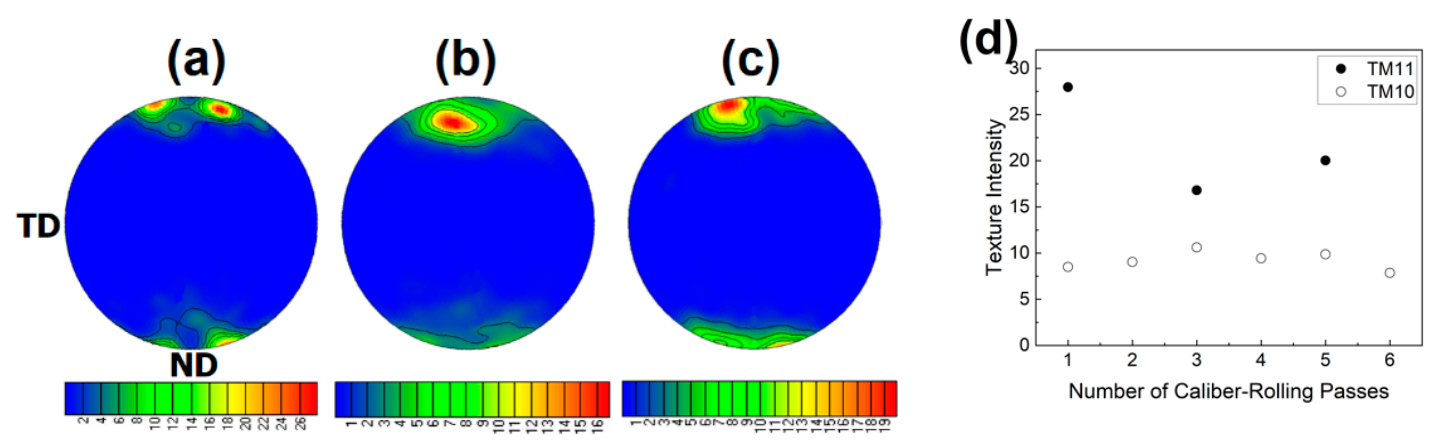

Figure 6. $\{0001\}$ pole figure maps of TM11 Mg alloys: (a) TM11-1P, (b) TM11-3P, and (c) TM11-5P; (d) texture intensities of the investigated TM10 and TM11 Mg alloys.

\section{Discussion}

Zhao et al. [23] compared $\mathrm{Mg}-x \mathrm{Sn}(x=1,2,3,4)$ alloys with respect to microstructures and strain-hardening behaviors. It should be noted that $\mathrm{Mg}-1 \mathrm{Sn}$ in their work corresponds to the present $\mathrm{TM} 10 \mathrm{Mg}$ alloy, although there is a difference in the plastic deformation processes (i.e., not in the caliber rolling, but extrusion). An excessive amount of $\mathrm{Sn}$ in the $\mathrm{Mg}-3 \mathrm{Sn}$ and $\mathrm{Mg}-4 \mathrm{Sn}$ alloys exhibited the precipitation of $\mathrm{Mg}_{2} \mathrm{Sn}$ particles. In contrast, Sn existed in the form of a solid solution in the alloys containing $1 \%$ or $2 \% \mathrm{Sn}$. Dynamic recrystallization occurred in all the $\mathrm{Mg}-\mathrm{Sn}$ alloys during the extrusion, because of which the grain size decreased with increasing Sn content. Mg-3Sn and $\mathrm{Mg}-4 \mathrm{Sn}$ alloys showed stronger recrystallization because the $\mathrm{Mg}_{2} \mathrm{Sn}$ precipitates acted as additional nucleation sites for recrystallization. However, these alloys resulted in an inhomogeneous distribution of grain sizes. The previous study rationalized the homogeneous microstructure without the $\mathrm{Mg}_{2} \mathrm{Sn}$ precipitates in the caliber-rolled TM10 Mg alloys.

Yu et al. [24] compared the microstructure of the $\mathrm{Mg}-1 \mathrm{Mn}$ alloy with that of pure $\mathrm{Mg}$. The former showed fine precipitates after extrusion at $523 \mathrm{~K}$. As a result, the Mn-containing alloy exhibited a considerable grain refinement to a grain size of $3.1 \mu \mathrm{m}$ compared to $13.8 \mu \mathrm{m}$, as observed in pure $\mathrm{Mg}$. According to Liao et al. [22], the grain-refining effect was enfeebled when the Mn content was increased from $1 \%$ to $2 \%$ because the formation of the coarse Mn-based precipitates rarely contributed to the pinning effect. These results provided a reasonable explanation for the significant grain refinement in the caliber-rolled TM11 Mg alloys, as compared with the TM10 Mg alloys, as shown in Figure 4.

An intrinsic feature of multi-pass caliber rolling is the alternating ND and TD per rolling pass, which caused a considerable amount of redundant strain. In other words, the strain generated at a single caliber-rolling pass $\left(\varepsilon_{p}\right)$ was considerably higher than the strain calculated in a conventional way $\left(\varepsilon_{r}\right)$, which is expressed as:

$$
\varepsilon_{r}=-\ln (1-r),
$$

where $r$ indicates a reduction in the area. Lee et al. [25] suggested a pass-by-pass strain model to consider the redundant strain generated at each rolling pass, expressed as follows:

$$
\begin{aligned}
& \varepsilon_{p}=\left(\varepsilon_{2} \sqrt{2} \sqrt{3}\right) {\left[1+\left(\varepsilon_{1} / \varepsilon_{2}\right)+\left(\varepsilon_{1} / \varepsilon_{2}\right)^{2}\right]^{1 / 2}, } \\
& \varepsilon_{1}=\ln \left(W_{p} / W_{i}\right), \\
& \varepsilon_{2}=\ln \left(H_{p} / H_{i}\right),
\end{aligned}
$$

the subscripts $i$ and $p$ indicate the state before and after the plastic deformation, respectively. The effective strain made by caliber rolling can thus be calculated from the sum of the corresponding $\varepsilon_{p}$ values. This result was close to the effective strain obtained through a finite-element (FE) analysis [26], which ensured the reliability of the data.

The effective strains calculated from the aforementioned equations were compared as a function of caliber rolling passes (Figure 7). The difference between the two types of strains rapidly increased with 
the increasing number of rolling passes. This implies a higher efficiency of multi-pass caliber rolling for straining and the resultant grain refinement. Furthermore, the caliber morphology adopted in this work also assisted in grain refinement through an effective strain distribution. The caliber morphology is classified into two categories: diamond-shaped and oval/circular-shaped. Inoue et al. [12] employed an FE analysis to calculate the strain distribution of AZ31 Mg alloy deformed through diamond-shaped calibers. According to their calculation, the diamond morphology gave rise to a strain accumulation around the corners of the cross-section. This type of strain distribution was also found in carbon steel deformed through diamond-shaped calibers [27], implying the primary role of the caliber morphology in strain distribution. In contrast, the center of the cross-section exhibited the highest strain, when an alloy was deformed through oval/circular calibers (i.e., the morphology adopted in this work) [28]. This state was beneficial for an efficient application of large strains and grain refinement. Moreover, the modification of the oval/circular calibers could further increase the uniformity of grain size and hardness depending on the position of the cross-sectional area [29]. These results justify the significant fine-grained structure of the caliber-rolled TM10 and TM11 Mg alloys as compared with their extruded counterparts.

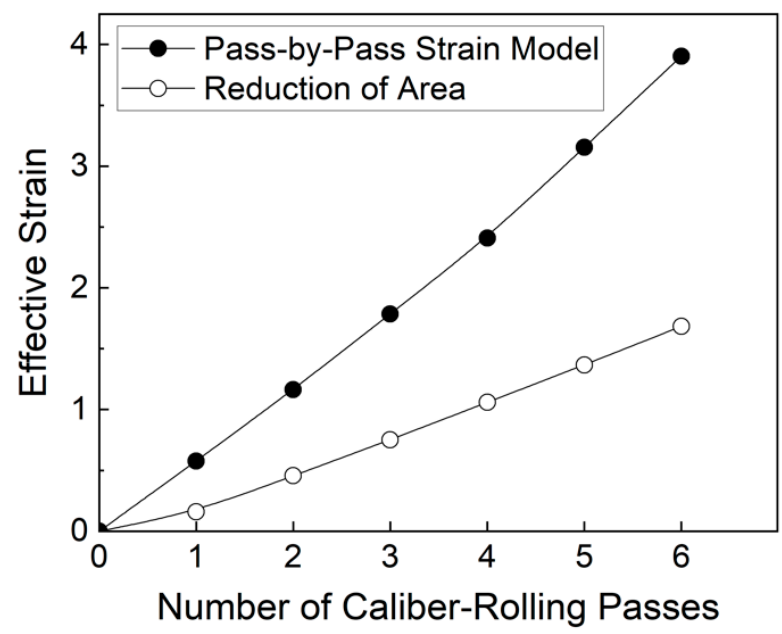

Figure 7. The effective strain of the caliber-rolled alloys calculated by the traditional approach using the reduction of area and the pass-by-pass strain model [25].

Lee et al. [26] calculated the strain distribution of a Ti alloy deformed by the caliber rolling machine used in this study. The six-pass caliber rolling (i.e., 6P) generated a high-strain regime around the center of the material cross-section, which accounted for $43 \%$ of the entire area. The deformation with the lower number of caliber rolling passes (i.e., from 1P to 5P) led to a more uniform distribution of the strain. A similar strain distribution was expected for the caliber-rolled TM10 and TM11 Mg alloys.

The alternating ND and TD deformations also gave rise to a unique spilt texture of the caliber-rolled $\mathrm{Mg}$ alloys. Such a texture has been reported in other $\mathrm{Mg}$ alloys subjected to caliber rolling, such as AZ31 [15] and ZK60 [17]. These results suggest that the caliber rolling process, rather than the alloying compositions, induced the split basal texture in the investigated Mg alloys. The split texture is an exclusive feature of the caliber-rolled Mg alloys, which is different from the basal texture of the rolled alloys [30] or the ring fiber texture of the extruded alloys [8,22,31]. Recently, Kwak et al. [18] elucidated the unique plastic anisotropic behavior of a caliber-rolled ZK60 Mg alloy possessing a split texture. The deformation behavior of the alloy under compression along the RD was similar to that of conventionally extruded Mg alloys, as characterized by a concave-upward flow curve. The similarity is attributed to the same alignment of the basal poles perpendicular to the RD in both the alloys, where the deformation was accommodated by an extension twinning [17]. Compressions along the ND and TD, however, resulted in different deformation characteristics between the two alloys owing to their inconsistent angles between the basal pole and compressive vector. The caliber-rolled TM10 and TM11 
Mg alloys exhibited similar textures as the caliber-rolled ZK60 alloys reported in the literature [18]. It is, therefore, deduced that the present alloys would behave in a similar way under compression along the RD, ND, and TD.

\section{Conclusions}

This work investigated the microstructural evolution of TM10 and TM11 Mg alloys subjected to various caliber rolling strains. Both alloys exhibited a decreasing grain size with an increase in the number of caliber-rolling passes. The grain structure was transformed from elongated to equiaxed with straining owing to the occurrence of recrystallization. $\mathrm{Mg}_{2} \mathrm{Sn}$ precipitation was inhibited as $\mathrm{Sn}$ existed in the form of a solid solution with 1\%-Sn addition. Compared to the TM10 Mg alloy, the TM11 $\mathrm{Mg}$ alloy exhibited finer microstructures under the same caliber rolling strain. This is attributed to the addition of $1 \%$ of Mn, which was accompanied by an efficient pinning effect. The caliber-rolled TM10 and TM11 Mg alloys exhibited significantly smaller grains than those of the extruded alloys, even at lower temperatures. This stemmed from the intrinsic feature of caliber rolling that ND and TD were replaced with each other during each rolling pass. This feature gave rise to a considerable amount of redundant strain. The oval/circular morphology of calibers also caused a concentration of strain at the center of the cross-sectional area, thereby assisting in effective grain refinement. The caliber-rolled alloys showed a basal texture where the basal poles were arranged perpendicular to the $\mathrm{RD}$, although the TM10-1P sample showed incomplete perpendicularity. Increasing the caliber rolling strains gave rise to a unique split of the basal poles owing to the alternating loading axes. The TM11 Mg alloys exhibited higher texture intensities than the TM10 Mg alloys.

Author Contributions: Conceptualization, T.L. and J.K.; methodology, J.K.; investigation, J.Y. and H.L.; resources, J.H.L., Y.H.M., H.S.Y., and J.K.; data curation, H.L.; original draft preparation, J.Y. and T.L.; review and editing of the draft, T.L. and J.K.; supervision, T.L.; and funding acquisition, T.L. All authors have read and agreed to the published version of the manuscript.

Funding: This work was supported by the National Research Foundation of Korea (NRF) through a grant funded by the Korean government (MSIT) through GCRC-SOP (No. 2011-0030013).

Conflicts of Interest: The authors declare no conflict of interest.

\section{References}

1. Luo, A.A. Magnesium casting technology for structural applications. J. Magnes. Alloys 2013, 1, 2-22. [CrossRef]

2. Golrang, M.; Mobasheri, M.; Mirzadeh, H.; Emamy, M. Effect of Zn addition on the microstructure and mechanical properties of Mg-0.5Ca-0.5RE magnesium alloy. J. Alloys Compd. 2020, 815, 152380. [CrossRef]

3. Kim, J.; Kawamura, Y. Influence of Rare Earth Elements on Microstructure and Mechanical Properties of Mg97Zn1Y1RE1 Alloys. Mater. Sci. Eng. A 2013, 573, 62-66. [CrossRef]

4. Go, J.; Lee, J.U.; Moon, B.G.; Yoon, J.; Park, S.H. Improvement in Mechanical Properties of Rolled AZ31 Alloy Through Combined Addition of Ca and Gd. Met. Mater. Int. 2020. [CrossRef]

5. Banijamali, S.M.; Palizdar, Y.; Najafi, S.; Sheikhani, A.; Nezhad, M.S.A.; Moghaddam, P.V.; Torkamani, H. Effect of Ce Addition on the Tribological Behavior of ZK60 Mg-Alloy. Met. Mater. Int. 2020, 1-11. [CrossRef]

6. Lu, F.; Ma, A.; Jiang, J.; Chen, J.; Song, D.; Yuan, Y.; Chen, J.; Yang, D. Enhanced mechanical properties and rolling formability of fine-grained $\mathrm{Mg}-\mathrm{Gd}-\mathrm{Zn}-\mathrm{Zr}$ alloy produced by equal-channel angular pressing. J. Alloys Compd. 2015, 643, 28-33. [CrossRef]

7. Park, S.H.; Kim, H.S.; Bae, J.H.; Yim, C.D.; You, B.S. Improving the mechanical properties of extruded Mg-3Al-1Zn alloy by cold pre-forging. Scr. Mater. 2013, 69, 250-253. [CrossRef]

8. Lee, T.; Yamasaki, M.; Kawamura, Y.; Go, J.; Park, S.H. High-Strength AZ91 Alloy Fabricated by Rapidly Solidified Flaky Powder Metallurgy and Hot Extrusion. Met. Mater. Int. 2019, 25, 372-380. [CrossRef]

9. Yu, H.; Park, S.H.; You, B.S. Development of extraordinary high-strength Mg-8Al-0.5Zn alloy via a low temperature and slow speed extrusion. Mater. Sci. Eng. A 2014, 610, 445-449. [CrossRef]

10. Chang, S.Y.; Lee, S.W.; Kang, K.M.; Kamado, S.; Kojima, Y. Improvement of Mechanical Characteristics in Severely Plastic-deformed Mg Alloys. Mater. Trans. 2004, 45, 488-492. [CrossRef] 
11. Kimura, Y.; Inoue, T.; Yin, F.; Tsuzaki, K. Inverse Temperature Dependence of Toughness in an Ultrafine Grain-Structure Steel. Science 2008, 320, 1057-1060. [CrossRef] [PubMed]

12. Inoue, T.; Somekawa, H.; Mukai, T. Hardness Variation and Strain Distribution in Magnesium Alloy AZ31 Processed by Multi-pass Caliber Rolling. Adv. Eng. Mater. 2009, 11, 654-658. [CrossRef]

13. Tripathi, A.; Murty, S.V.S.N.; Narayanan, P.R. Microstructure and texture evolution in AZ31 magnesium alloy during caliber rolling at different temperatures. J. Magnes. Alloys 2017, 5, 340-347. [CrossRef]

14. Lee, J.H.; Kwak, B.J.; Kong, T.; Park, S.H.; Lee, T. Improved tensile properties of AZ31 Mg alloy subjected to various caliber-rolling strains. J. Magnes. Alloys 2019, 7, 381-387. [CrossRef]

15. Kong, T.; Kwak, B.J.; Kim, J.; Lee, J.H.; Park, S.H.; Kim, J.H.; Moon, Y.H.; Yoon, H.S.; Lee, T. Tailoring strength-ductility balance of caliber-rolled AZ31 Mg alloy through subsequent annealing. J. Magnes. Alloys 2020, 8, 163-171. [CrossRef]

16. Stefanik, A.; Szota, P.; Mróz, S.; Bajor, T.; Dyja, H. Properties of the AZ31 Magnesium Alloy Round Bars Obtained in Different Rolling Processes. Arch. Metall. Mater. 2015, 60, 3001-3006. [CrossRef]

17. Lee, T.; Kwak, B.J.; Kong, T.; Lee, J.H.; Lee, S.W.; Park, S.H. Enhanced yield symmetry and strength-ductility balance of caliber-rolled Mg-6Zn-0.5Zr with ultrafine-grained structure and bulk dimension. J. Alloys Compd. 2019, 803, 434-441. [CrossRef]

18. Kwak, B.J.; Park, S.H.; Moon, Y.H.; Lee, J.H.; Lee, T. Plastic anisotropy of multi-pass caliber-rolled Mg alloy with split texture distribution. Mater. Sci. Eng. A 2020, 788, 139496. [CrossRef]

19. Somekawa, H.; Basha, D.A.; Singh, A. Change in dominant deformation mechanism of Mg alloy via grain boundary control. Mater. Sci. Eng. A 2019, 746, 162-166. [CrossRef]

20. Liu, N.; Chen, L.; Fu, Y.; Zhang, Y.; Tan, T.; Yin, F.; Liang, C. Interfacial characteristic of multi-pass caliber-rolled Mg/Al compound castings. J. Mater. Process. Technol. 2019, 267, 196-204. [CrossRef]

21. Zhou, Y.; Wu, P.; Yang, Y.; Gao, D.; Feng, P.; Gao, C.; Wu, H.; Liu, Y.; Bian, H.; Shuai, C. The microstructure, mechanical properties and degradation behavior of laser-melted MgSn alloys. J. Alloys Compd. 2016, 687, 109-114. [CrossRef]

22. Liao, H.; Kim, J.; Liu, T.; Tang, A.; She, J.; Peng, P.; Pan, F. Effects of Mn addition on the microstructures, mechanical properties and work-hardening of Mg-1Sn alloy. Mater. Sci. Eng. A 2019, 754, 778-785. [CrossRef]

23. Zhao, C.; Chen, X.; Pan, F.; Gao, S.; Zhao, D.; Liu, X. Effect of Sn content on strain hardening behavior of as-extruded Mg-Sn alloys. Mater. Sci. Eng. A 2018, 713, 244-252. [CrossRef]

24. Yu, Z.; Tang, A.; Wang, Q.; Gao, Z.; He, J.; She, J.; Song, K.; Pan, F. High strength and superior ductility of an ultra-fine grained magnesium-manganese alloy. Mater. Sci. Eng. A 2015, 648, 202-207. [CrossRef]

25. Lee, Y.; Choi, S.; Hodgson, P.D. Analytical model of pass-by-pass strain in rod (or bar) rolling and its applications to prediction of austenite grain size. Mater. Sci. Eng. A 2002, 336, 177-189. [CrossRef]

26. Lee, T.; Park, K.-T.T.; Lee, D.J.; Jeong, J.; Oh, S.H.; Kim, H.S.; Park, C.H.; Lee, C.S. Microstructural evolution and strain-hardening behavior of multi-pass caliber-rolled Ti-13Nb-13Zr. Mater. Sci. Eng. A 2015, 648, 359-366. [CrossRef]

27. Inoue, T.; Yin, F.; Kimura, Y. Strain distribution and microstructural evolution in multi-pass warm caliber rolling. Mater. Sci. Eng. A 2007, 466, 114-122. [CrossRef]

28. Inoue, T. Optimum pass design of bar rolling for producing bulk ultrafine-grained steel by numerical simulation. Mater. Sci. Forum 2010, 654-656, 1561-1564. [CrossRef]

29. Szota, P.; Mróz, S.; Stefanik, A.; Mola, R. Analysis of the AZ31 magnesium alloy bars rolling process in modified stretching passes. Mater. Sci. Eng. Technol. 2015, 46, 285-293. [CrossRef]

30. Park, S.H.; Hong, S.-G.; Lee, C.S. Activation mode dependent $\left\{\begin{array}{llll}1 & 0 & -1 & 2\end{array}\right\}$ twinning characteristics in a polycrystalline magnesium alloy. Scr. Mater. 2010, 62, 202-205. [CrossRef]

31. Kim, S.H.; Jo, W.K.; Hong, W.H.; Kim, W.; Yoon, J.; Park, S.H. Microstructural evolution of extruded AZ31 alloy with bimodal structure during compression. Mater. Sci. Eng. A 2017, 702, 1-9. [CrossRef]

(C) 2020 by the authors. Licensee MDPI, Basel, Switzerland. This article is an open access article distributed under the terms and conditions of the Creative Commons Attribution (CC BY) license (http://creativecommons.org/licenses/by/4.0/). 